\title{
CHRONIC SUPPURATIVE OTITIS MEDIA AND SENSORINEURAL HEARING LOSS
}

Naveen Kumar A. G1, Ravikeerthi G²

\section{HOW TO CITE THIS ARTICLE:}

Naveen Kumar A. G, Ravikeerthi G. "Chronic Suppurative Otitis Media and Sensorineural Hearing Loss". Journal of Evolution of Medical and Dental Sciences 2015; Vol. 4, Issue 67, August 20; Page: 11595-11599,

DOI: $10.14260 /$ jemds/2015/1674

\begin{abstract}
BACKGROUND: Chronic suppurative otitis media is a common disease affecting young age group, it is typically a persistent disease, often capable of causing severe destruction and irreversible sequelae and clinically manifest with deafness and discharge. OBJECTIVES: To evaluate the degree of sensorineural hearing loss component in patients with chronic suppurative otitis media with and without pathological sequelae, which necessitate early detection as it increase in severity with time. METHODS: A prospective study of 140 patients with unilateral chronic suppurative otitis media was evaluated otologically and audiologically for bone conduction hearing loss in the diseased ear throughout one year. The patients mean age was $26.5 \pm 0.5$ years ranging from $10-45$ years and the mean duration of the illness were $6.9 \pm 2.5$ years ranging from 1-30 years. RESULTS: Eighty-eight and a half percent of the patients with unilateral chronic suppurative otitis media had some loss of cochlear function. CONCLUSION: Most patients had a difference of less than $10 \mathrm{db}$ in bone conduction between diseased and uninvolved ears. The range difference between diseased and uninvolved ears was wider at the higher frequencies, related mainly to the duration of the disease and its pathological sequelae such as cholesteatoma and or granulation tissue.
\end{abstract}

KEYWORDS: Sensorineural, otitis media, round window, Cholesteatoma.

INTRODUCTION: Chronic suppurative otitis media is an inflammation of part or all of the mucoperiosteal lining of middle ear cleft. The disease has 2 types; mucosal chronic suppurative otitis media and squamous epithelial disease (Cholesteatoma). All perforations of pars tensa are central indicative of tubo-tympanic disease. All attic disease is attico- antral and marginal.

The typical feature of atticoantral disease is the presence of a cholesteatoma (Keratinizing squamous epithelium in the middle ear cleft.(1) The bony involvement by the disease may give rise to granulation or polyp.

Round window membrane is the only soft tissue barrier separating the middle ear from the inner ear this semipermeable membrane appears to be the main portal for the passage of noxious substance from the middle ear cavity to the labyrinth. The round window membrane in chronic suppurative otitis media commonly changes its thickness 3-5 times than that of the control.(2)

Round window membrane is permeable to certain biological substance which has the potential to cause inner ear damage leading to functional disturbance,(3) it is known that endotoxin alter the permeability and penetrate the round window membrane to cause transient dysfunction of inner ear.

Paparella et al (1972) reported the presence of serofibrinous and inflammatory cells in the cochlea of mostly adult patients with chronic suppurative otitis media,(4) they thought that clinically observed sensorineural hearing loss result from inflammatory and immunological effect.(4) 


\section{ORIGINAL ARTICLE}

The chronic inflammatory process can produce some circulatory disturbance such as vasodilatation and vasoconstriction of the mucosal vessels of the round window membrane which could influence the inner ear.(5)

METHODS: This study was carried on 140 patients complaining of long standing unilateral chronic suppurative otitis media prospectively studied and to evaluate the effect of chronic suppurative otitis media on sensorineural hearing loss.

The patients were selected in accordance with clinical criteria of at least one year prior to inclusion in this study as prerequisite for selection the normal ear was taken as control. The age ranged from 10-45 years. We considered the age, sex, duration, size, and site of the perforation and whether the ear is dry or wet.

After the patients were being examined clinically they were evaluated by pure tone audiometry examination. Bone conduction thresholds were measured at frequencies $(500,1000$, $2000,4000 \mathrm{H} 2$ ) utilizing diagnostic audiometer model TA 155. The opposite ear was always masked while bone conduction results were obtained, statistical analyses used normal distribution statistics and unpaired t-test distribution to determine significant differences between variables.

RESULTS: The male percentage was $(47.2 \%)$ while female percentage was $(52.8 \%),(58.5 \%)$ were right diseased ears and (41.5\%) were left diseased ears. The mean age were $26.5 \pm 0.5$ years ranging from $10-45$ years. Discharging ears formed $77.2 \%$ while only $22.8 \%$ were dry at the examination. Sixty-Two and eight percent of patients complained of tinnitus at the time of examination.

Eighty-eight and half percent of the patients with unilateral chronic suppurative otitis media had some loss of cochlear function as showed by pure tone audiometry.

Table 1 shows the distribution of patients according to duration of pathology the mean duration of illness was $6.9 \pm 2.5$ years ranging from 1-30 years. Table 2 shows the distribution of patients according to the type of pathology.

\begin{tabular}{|c|c|c|}
\hline $\begin{array}{c}\text { Duration } \\
\text { [Years] }\end{array}$ & $\begin{array}{c}\text { Number } \\
\text { of Patients }\end{array}$ & $\begin{array}{c}\text { \% } \\
\text { Percentage }\end{array}$ \\
\hline $1-5$ & 84 & $60 \%$ \\
\hline $6-10$ & 26 & $18.57 \%$ \\
\hline $11-15$ & 12 & $8.57 \%$ \\
\hline $16-20$ & 12 & $8.57 \%$ \\
\hline$>20$ & 6 & $4.28 \%$ \\
\hline \multicolumn{2}{|c|}{ Table 1: Distribution of the Patients } \\
According to the Type of Pathology \\
\hline
\end{tabular}

\begin{tabular}{|c|c|c|}
\hline Pathology & No. of Patients & $\%$ Percentage \\
\hline Perforated TM & 104 & $74.28 \%$ \\
\hline Granulation or polyp & 24 & $17.14 \%$ \\
\hline Cholsteatoma & 12 & $8.57 \%$ \\
\hline
\end{tabular}




\section{ORIGINAL ARTICLE}

TM: Tympanic Membrane: Table 3 shows the mean and median bone conduction in $\mathrm{dB}$ of each frequency in the normal ears and diseased ears.

Table 4 shows mean bone conduction hearing threshold at each frequency in the diseased ear in relation to the duration of pathology.

It shows increase hearing loss with increasing duration of pathology this relation was statistically significant $(p>0.05)$. There is $15 \mathrm{~dB}$ or greater bone conduction hearing loss at one frequency or more in $42.8 \%$ of the patients involved in the study and there is $15 \mathrm{~dB}$ or greater hearing loss at two frequencies or more in $21.4 \%$ of the patients

Table 5 shows mean bone conduction hearing thresholds at each frequency in relation to the type of pathology. There is increase in bone conduction hearing threshold with granulation tissue, polyp, and cholesteatoma. This relation was statistically significant $(\mathrm{p}<0.01)$. The site and size of the perforation have no significant effect on bone conduction of diseased ear.

\begin{tabular}{|c|c|c|c|c|}
\hline & Frequency (Hz) & Mean (dB) & Median (dB) & Range (dB) \\
\hline \multirow{4}{*}{ Normal ear } & 500 & $5.85 \pm 0.14$ & 5 & $0-30$ \\
& 1000 & $7.42 \pm 0.12$ & 5 & $0-35$ \\
& 2000 & $9.50 \pm 0.1$ & 10 & $0-35$ \\
& 4000 & $10.71 \pm 0.09$ & 10 & $0-50$ \\
\hline \multirow{4}{*}{ Diseased ear } & 500 & $9.00 \pm 0.19$ & 10 & $0-40$ \\
& 1000 & $13.00 \pm 0.16$ & 10 & $0-45$ \\
& 2000 & $16.57 \pm 0.13$ & 15 & $0-50$ \\
& 4000 & $21.00 \pm 0.12$ & 20 & $0-60$ \\
\hline
\end{tabular}

Table 3: Bone conduction in $\mathrm{dB}$ at each frequency in normal and Diseased Ear

\begin{tabular}{|c|c|c|c|c|}
\hline $\begin{array}{c}\text { Duration } \\
\text { (years) }\end{array}$ & $\mathbf{5 0 0 H z}$ & $\mathbf{1 0 0 0 H z}$ & $\mathbf{2 0 0 0 H z}$ & $\mathbf{4 0 0 0 H z}$ \\
\hline $1-5$ & $6.07 \pm 0.7$ & $8.45 \pm 0.4$ & $13.09 \pm 0.2$ & $17.50 \pm 0.09$ \\
$6-10$ & $10.38 \pm 0.4$ & $15.38 \pm 0.35$ & $16.15 \pm 0.25$ & $20.76 \pm 0.15$ \\
$11-15$ & $13.30 \pm 0.3$ & $21.60 \pm 0.2$ & $23.30 \pm 0.09$ & $27.50 \pm 0.85$ \\
$16-20$ & $17.50 \pm 0.2$ & $25.00 \pm 0.09$ & $28.30 \pm 0.07$ & $33.33 \pm 0.06$ \\
$>20$ & $20.00 \pm 0.1$ & $26.60 \pm 0.08$ & $30.00 \pm 0.05$ & $36.60 \pm 0.04$ \\
\hline
\end{tabular}

Table 4: Bone conduction in $\mathrm{dB}$ in the diseased ear at each frequency in relation to duration of pathology

\begin{tabular}{|l|l|c|c|c|}
\hline \multicolumn{1}{|c|}{ Pathology } & $\mathbf{5 0 0 H z}$ & $\mathbf{1 0 0 0 H z}$ & $\mathbf{2 0 0 0 H z}$ & $\mathbf{4 0 0 0 H z}$ \\
\hline Perforated tympanic membrane & $8.60 \pm 0.45$ & $10.48 \pm 0.4$ & $15.60 \pm 0.2$ & $20.38 \pm 0.15$ \\
Polyp or granulation tissue & $13.75 \pm 0.35$ & $15.41 \pm 0.25$ & $19.58 \pm 0.2$ & $22.50 \pm 0.1$ \\
Cholesteatoma & $13.33 \pm 0.3$ & $15.80 \pm 0.2$ & $20.80 \pm 0.15$ & $23.30 \pm 0.09$ \\
\hline
\end{tabular}

Table 5: Bone Conduction Threshold according to the Pathology at each Frequency 


\section{ORIGINAL ARTICLE}

\begin{tabular}{|c|c|c|c|c|}
\hline & Frequency & $\begin{array}{c}\text { Bone } \\
\text { Conduction }\end{array}$ & $\begin{array}{c}\text { Difference } \\
\text { Square }\end{array}$ & $\begin{array}{c}\text { Difference } \\
\text { (dB) }\end{array}$ \\
\hline & \multicolumn{2}{|c|}{ Diseased Ear (dB) } & Normal Ear (dB) \\
\hline $500(\mathrm{~dB})$ & 9.0 & 5.85 & 3.15 & 9 \\
$1000(\mathrm{~dB})$ & 13.0 & 7.42 & 5.58 & 31 \\
$2000(\mathrm{~dB})$ & 16.57 & 9.50 & 9.07 & 82 \\
$4000(\mathrm{~dB})$ & 21.00 & 10.71 & 10.29 & 105 \\
\hline Total & $\mathbf{5 9 . 5 7}$ & $\mathbf{3 3 . 4 8}$ & $\mathbf{2 8 . 0 9}$ & $\mathbf{2 2 7}$ \\
\hline \multicolumn{6}{|c|}{ Table 6: Bone Conduction difference in the Diseased } \\
and Normal Ear calculated by t- test \\
\hline
\end{tabular}

DISCUSSION: Our results shows there is a difference in bone conduction thresholds between diseased and control ears at all frequencies particularly at higher frequencies, this difference increase with duration and the presence of pathological sequelae such as a cholsteatoma, granulation tissue and polyps these results agrees with the majority of studies done on this subject .

The mean bone conduction difference for pure tone average was $6.52 \pm 2.5 \mathrm{~dB}$, median of $6.3 \mathrm{~dB}$ this finding is in agreement with that result obtained by Dumich et al (1983) who noted median bone conduction threshold difference between diseased and uninvolved ear with in $5 \mathrm{~dB} .{ }^{(6)}$

However it has been reported by Levine et al (1989) that the majority of patients had little difference between diseased and control ears the mean bone conduction difference for the pure tone average was $9.1 \mathrm{~dB}$ across the frequencies. (7)

Rice found sensorineural hearing loss of $20 \mathrm{~dB}$ or more in $34 \%$ of 225 consecutive ears undergoing tympanoplasty for various reasons.(7) Cusimano et al (1989) reported an increased mean bone conduction difference of $5.5 \mathrm{~dB}$ for every ten years duration of chronic otitis media.(5)

A 24 percent of sensoineural hearing loss was found, garticularly involving the higher frequencies. Moreover, the incidence of sensorineural hearing loss progressively increased with the increase in duration of chronic suppurative Otitis media.[8] SNHL occurred in 13\% of the patients with CSOM, and was correlated with older age, but not with the presence of cholesteatoma or longer duration of ear disease. ${ }^{(9)}$

The bone-conduction threshold averages for the normal side were lower than those for the ear with chronic otitis media. The threshold shift was statistically significant for each frequency $(\mathrm{P}<0.0001$, Student's T test).

There were differences between the groups when analyzed for age (500 and 1,000Hz) or the presence of cholesteatoma $(1,000 \mathrm{~Hz})$. This study shows that chronic otitis media is associated with a decrease in cochlear function.(10) In our study some patients showed better bone conduction in the diseased ear, this agrees with finding of Dumich et al (1983).(6)

CONCLUSION: The majority of patients with chronic suppurative otitis media had little difference in bone conduction between diseased and control ear, clinically significant sensorineural hearing loss is uncommon.

In spite of extensive middle ear and mastoid disease were found causing significant loss of cochlear function, high frequencies were more affected. 


\section{ORIGINAL ARTICLE}

Statistically significant sensorineural hearing loss was related to the duration of the disease and its pathological sequelae such as cholesteatoma and granulation tissue.

Sensorineural hearing loss in chronic suppurative otitis media is not as prevalent as expected to the relatively prevalent otitis media; it seems that the round window membrane provides a protective barrier to the passage of toxic materials through it to the cochlea.

\section{REFERENCES:}

1. Browning GG, Burton MJ, Clarke R, et al. Scott Brown's Otorhinolaryngology, Head and Neck Surgery Michael Gleeson, 7th ed UK, 2008; 237c: 3409-17.

2. Hellstrom S, Johhansson U, Anniko M. Structure of the round window membrane. Acta Otolaryngologica 1988; 457: 33-42.

3. Tos M. Sensorineural hearing loss in acute and chronic middle ear disease. Acta Otolaryngologica 1988; 457: 89-93.

4. Paparella MM, Morinzo T, Le CT, et al. Sensorineural hearing loss in otitis media. Ann Otol Rhinol Laryngol 1984; 93: 623-629.

5. Cusimano F, Cocita VC, D'Amico A. Sensorineural hearing loss in chronic otitis media. J Laryngol Otol 1989 Feb.; 103: 158-163.

6. Dumich PS, Harner SG. Cochlear function in chronic otitis media. Laryngoscope 1984; 93: 583586.

7. Levine BA, Shelton C, Berliner KI, et al. Sensorineural hearing loss in chronic otitis media. Is it clinically significant? Arch Otolaryngol Head Neck Surg 1989; 115(7): 814-81.

8. Kaur K, Sonkhya N, Bapna AS. Chronic suppurative otitis media and sensorineural hearing loss: Is there a correlation? Indian J Otolaryngol Head Neck Surg 2003; 55(1): 21-24.

9. De Azevedo AF, Gomes-Pinto DC. Sensorineural hearing loss in chronic suppurative otitis media with and without cholesteatoma. Rev Bras Otolaryngol 2007; 73(5): 671-4.

10. da Costa SS, Schmidt-Rosito LP, Dornelles C. Sensorineural hearing loss in patients with chronic otitis media. Eur Arch Oto Rhino Laryngol 2009; 266(2): 221-224.

\section{AUTHORS:}

1. Naveen Kumar A. G.

2. Ravikeerthi G.

\section{PARTICULARS OF CONTRIBUTORS:}

1. Assistant Professor, Department of ENT, Sapthagiri Institute of Medical Sciences and Research Centre, Bangalore.

2. Assistant Professor, Department of ENT, Sapthagiri Institute of Medical Sciences and Research Centre, Bangalore.

\section{FINANCIAL OR OTHER} COMPETING INTERESTS: None
NAME ADDRESS EMAIL ID OF THE CORRESPONDING AUTHOR:

Dr. Naveen Kumar A. G, Assistant Professor, Department of ENT, Sapthagiri Institute of Medical Sciences and Research Centre, Bangalore-90.

E-mail: agnaveen27@yahoo.com

Date of Submission: 06/08/2015. Date of Peer Review: 07/08/2015. Date of Acceptance: 17/08/2015. Date of Publishing: 18/08/2015. 